ISSN electrónico: 2172-9077

DOI: https://doi.org/10.14201/fjc20191999116

\title{
JOHN AKOMFRAH E ISAAC JULIEN: MIGRANDO ENTRE IDEAS, FORMAS Y PLATAFORMAS DE EXHIBICIÓN
}

\section{John Akomfrah and Isaac Julien: Migrating between ideas, formas and exhibition platforms}

\author{
Beatriz LEAL RIESCO \\ Investigadora independiente. Profesora en la UNED (Tudela), España. \\ E-mail: leal78@gmail.com \\ (iD) http://orcid.org/0000-0003-4851-5583
}

Fecha de recepción del artículo: 15/09/2019

Fecha de aceptación definitiva: 23/10/2019

\begin{abstract}
RESUMEN
Los artistas afro-diaspóricos Isaac Julien (Londres, 1960) y John Akomfrah (Ghana, 1957) se han hecho en la última década con salas de museos y galerías internacionales. A través de sus escritos, su presencia pública y unas trayectorias dilatadas con obras que transitan entre espacios (sala de cine, pantalla de televisión, cubo blanco), han adquirido una posición única entre la diáspora negra que les permite dedicarse con libertad a complejas obras multipantalla. En sus recientes obras-manifiesto 'Purple' (Akomfrah, 2018) y 'Playtime' y 'Kapital' (Julien, 2013-4) despliegan estrategias y herramientas formales que resitúan nuestra percepción, invitándonos a reflexionar sobre diversas emergencias actuales: la crisis ecológica y el calentamiento global, las guerras, los desplazamientos y flujos migratorios, o los efectos del neoliberalismo y el capitalismo racial global. El lenguaje audiovisual renovado que surge de estos ensayos audiovisuales multipantalla tienen como efecto el crear nuevas formas críticas y radicales de percepción entre la audiencia.
\end{abstract}

Palabras clave: arte contemporáneo; post-cine; ensayo fílmico; diáspora africana.

\begin{abstract}
The Afro-diasporic artistsan Isaac Julien (Londres, 1960) and John Akomfrah (Ghana, 1957) have overtaken international museums and galleries in recent years. Their writings, their public presentations, and their extensive careers, with works that travel across numerous spaces (cinema, television screen, white cube) have reached a unique position among those of the black diaspora, have allowed them to devote themselves freely to multi-screen works. In their recent manifesto works 'Purple' (Akomfrah, 2018) and 'Playtime' and 'Kapital' (Julien, 2013-4), they reveal strategies and formal tools that resituate our perceptions, inviting us to reflect on an array of contemporary emergencies: the ecological crisis, global warming, and racialized global capitalism. The transformed audiovisual language that emerges from their essayistic works in the multi-screen format creates new critical and radical forms of perception among audiences.
\end{abstract}

Key words: contemporary art; post-cinema; film essay; African diaspora. 
"Why make moving-image works, or films, for somewhere other than the cinema? In making 'WESTERN UNION: Small Boats' in 2007, I was interested in developing that question and in expanding the whole notion of the multi-screen installation work. In an increasingly troubled time of emergencies, war, and disinformation, moving images in a gallery context could represent an alternative view. "Isaac Julien. (Alter, 2017, p.336).

«For John Akomfrah, a key term in understanding cinema is 'migration,' as ideas, form, and exhibition platforms. How does cinema migrate into the art-exhibition space? What is lost and what is gained by such movements across very different institutions and viewing platforms?"(Alter, 2017, p.16).

\section{Introducción}

El siglo XXI se caracteriza por un estado de alerta constante en el ser humano derivado del flujo de información de Internet y las redes sociales que le llega a través de las omnipresentes pantallas. Este bombardeo de imágenes y datos, sin jerarquías ni filtros y con el tamiz igualador de lo digital, ha aumentado la dificultad para dar sentido a lo real y proponer ideas y filosofías desde la escritura. Partiendo de experiencias previas del cine-ensayo y dentro del espacio de la galería, las últimas obras multipantalla de los afro-británicos Isaac Julien y John Akomfrah se valen de estrategias y herramientas formales que resitúan nuestra percepción, invitándonos a reflexionar sobre diversas emergencias actuales: la crisis ecológica y el calentamiento global, las guerras, los desplazamientos humanos y flujos migratorios, y los efectos del neoliberalismo y el capitalismo global en los más desfavorecidos.

Cuando desconectarse y tomar distancia con el mundo se ha vuelto un esfuerzo titánico para hombres y mujeres con menguante capacidad de concentración, las obras-manifiesto 'Purple' (2018) de Akomfrah o 'Playtime' y 'Kapital' (2014) de Julien, son especialmente pertinentes. Miembros de la diáspora negra global, Akomfrah y Julien han alcanzado reconocimiento en los últimos años como artistas visuales en una era "post-cinemática", con instalaciones multipantalla en bienales, museos y galerías de prestigio. Sus trayectorias dilatadas abarcan más de tres décadas, cubriendo producciones de videoarte e instalaciones experimentales independientes, pasando por documentales, películas de ficción y ensayos fílmicos para cine y televisión. Desde que en los años 80s vieran luz sus primeras realizaciones colectivas, su praxis artística, su escritura crítica y su diálogo constante con filósofos y pensadores de diversas disciplinas, demuestran su objetivo por combinar un discurso filosófico y una práctica artística radicales en lo político-formal. Sus escritos críticos y teóricos, conferencias, proyectos de comisariado, y cursos y talleres en universidades, los sitúa en una posición ventajosa en la producción del discurso. Las palabras de la comisaria y filófosa afro-belga Nadia Yala Kisukidi, esclarecen la sintonía de Akomfrah y Julien con el momento actual:

On ne fait pas d'art aujourd'hui sans théoriser sa pratique. Et cette théorisation que font les artistes, c'est une pratique philosophique. C'est-à-dire que nos artistes contemporains sont tous des philosophes. Dans le champ de l'art contemporain, la philosophie, la production du discours comme tel fait partie de la performance artistique (Lokale : 2019). 
Evitando la simplificación o asimilación, los escritos teóricos y apariciones públicas de estos artistas ejercen bien como textos de presentación o como explicación a posteriori de la obra, elucidando su praxis y su filosofía. Este trabajo autoral de guía es particularmente claro en las publicaciones de Julien y su cuidada web, de excelente diseño y sencillo acceso constantemente actualizada, mientras el discurso de Akomfrah se manifiesta en sus apariciones públicas y escritos.

Parte de un grupo de creadores negros británicos que irrumpieron con fuerza en los años 80s del siglo pasado, John Akomfrah e Isaac Julien han logrado un reconocimiento y proyección internacionales sin parangón frente a otros artistas negros. Para entenderlos, hay que añadir a las particularidades históricas del contexto británico y londinense, su capacidad de diagnóstico y respuesta a las ansiedades individuales y colectivas provocadas por cambios en el planeta desde la caída del muro de Berlín en 1989, la desaparición del bloque del este y la consolidación global del capitalismo financiero.

Los efectos de este nuevo orden mundial en el ámbito lo político, histórico, artístico, ecológico y tecnológico se manifestó con contundencia en Occidente con la crisis financiera de 2007-8, azotando a las poblaciones más débiles y aumentando los desplazamientos humanos mientras revitalizaba el mercado del arte. El 1\% planetario, que ha visto aumentar su riqueza como nunca, confía en el mercado del arte por su materialidad y riesgo menor frente a las vicisitudes de lo que Michael A. Peters llama "Capitalismo algorítmico". El apetito fetichista de este mercado por nuevas obras y autores ha otorgado un valor económico sin precedentes a artistas afro-diaspóricos. Apoyados por una élite africana y diaspórica coleccionista con alta capacidad adquisitiva, devenida en mecenas de «su comunidad», los artistas africanos reflejan desde hace años su identidad híbrida, en constante transformación y flujo dada su condición de emigrantes, característica definitoria del hombre contemporáneo. En clara oposición a conceptos esencialistas (sostenidas por nacionalismos extremistas) dos nombres destacan por su reflexión sobre la cuestión de la identidad fragmentada, ligada a rutas y no a raíces: el teórico cultural jamaicano fundador de la 'New Left' británica, Stuart Hall y el filósofo e intelectual camerunés profesor en Wits Institute de Sudáfrica, Achille Mbembe.

Thinking about my own sense of identity, I realize that it has always depended on the fact of being a 'migrant,' on the 'difference' from the rest of you. So one of the fascinating things about this discussion is to find myself centered at last. Now that, in the postmodern age, you all feel dispersed, I become centered. What I've thought of as dispersed and fragmented comes, paradoxically, to be the representative modern experience! This is 'coming home' with a vengeance... (Hall, 1987, p. 44).

Traverser le monde, prendre la mesure de l'accident que représente notre lieu de naissance et son pesant d'arbitraire et de contrainte, épouser l'irréversible flux qu'est le temps de la vie et l'existence, apprendre à assumer notre statut de passant en tant que ceci est peut-être la condition en dernière instance de notre humanité, le socle à partir duquel nous créons la culture. ... Devenir-homme-dans-le-monde n'est ni une question de naissance ni une question d'origine ou de race. C'est une affaire de trajet, de circulation et de transfiguration (Mbembe, 2018, pp. 175-176).

Esta cambiante situación del mundo del arte y cultura globales ha sido vivida en carne propia por artistas como Julien y Akomfrah, ejemplares en su capacidad de responder a sus limitaciones y subvertir expectativas ligadas a su condición de 
sujetos negros. Su habilidad para transitar entre espacios según se iban abriendo o cerrando puertas, les ha permitido alcanzar una (tardía) aclamación universal en las mecas del arte contemporáneo (bienales, universidades, museos y galerías). La revisión de algunos de sus últimos trabajos me permitirá reflexionar sobre aspectos político-económicos e institucionales del mundo del post-cine y el arte contemporáneo (tanto a nivel de políticas nacionales como del mercado del arte y el audiovisual global); mostrar su encuentro con una audiencia internacional y local diversificada (¿se produce el acto comunicativo o, por el contrario, se refugian en el ejercicio de la ambigüedad, el relativismo y la opacidad de buena parte del arte contemporáneo?) para, finalmente, revisar las posibilidades críticas de obras que forman parte del canon de la historia del cine y el arte universales.

\section{John Akomfrah e Isaac Julien: respuestas en tiempos de crisis}

John Akomfrah nació en 1957 en Accra, dos meses después de que Ghana lograse la independencia y Kwame Nkrumah se convirtiese en su primer presidente. El fallecimiento del progenitor (de la órbita de Nkrumah), el activismo de su madre y la inseguridad que provocaría en 1966 el golpe de estado y el consiguiente exilio del presidente a Guinea, motivarían que la madre emigrase con sus hijos a Londres, donde Akomfrah ha desarrollado su carrera y vida personal. Isaac Julien nació en la capital británica en 1960 de una pareja originaria de la caribeña isla de Santa Lucía. Sus padres formaban parte de la mítica ${ }^{1}$ 'Windrush Generation'; primera ola de emigración de hombres y mujeres desde diversos territorios de la Commonwealth al Reino Unido para cubrir la escasez de mano de obra de la postguerra. Tanto Akomfrah como Julien son alumnos destacados de una generación sucesiva rupturista: «los hijos bastardos del 68', los chicos y chicas 'soul' del 77, la clase del 81'”, (Julien and MacCabe, 1991:65). Esta "clase del 81", reunía a un conjunto de jóvenes que había acabado sus estudios técnicos o universitario en el año en que se produjeron revueltas ('riots') en varias ciudades de Inglaterra. De abril a junio de 1981, la tensión racial y el abandono de los barrios populares, algunos casi inhabitables y con altas tasas de desempleo (en buena medida motivadas por las políticas de Margaret Thatcher), además de contados ataques policiales a jóvenes negros, serían los detonantes de las revueltas en Brixton (Londres) y en el barrio de Handsworth, en Liverpool, entre otros. La respuesta oficial y la representación prejuiciada de los medios de comunicación sobre las revueltas y sus protagonistas hicieron tomar partido a Akomfrah y Julien, quienes en sus primeras obras colaborativas se lanzaron a "corregir» la representación y ofrecer nuevas historias y sensibilidades de hombres y mujeres afro-británicos.

En este ambiente enrarecido, las instituciones públicas respondieron a la demanda de nuevas voces, historias y perspectivas de la población diaspórica en el cine y la televisión, tratando de paliar la dificultad de acceso a medios de producción audiovisuales. Gracias al apoyo y patrocinio de iniciativas culturales negras por parte del

1. En 2018 Theresa May pidió perdón a doce países caribeños por el «escándalo Windrush". Las nuevas políticas migratorias restrictivas tras la votación a favor del Brexit crearon ansiedad entre la población que, de 1947 a 1971, había emigrado al Reino Unido para cubrir puestos de trabajo y que, por no haber formalizado su situación de ciudadanía, sufrieron situaciones dramáticas como la deportación o negación de servicios sociales al carecer de documentos acreditativos. 
British Film Institute (BFI), Channel Four y el Great London Council (1982-86), se realizaron simposios y congresos ('Third Eye' en 1985 por Parminder Vir y June Givanni y el famoso congreso en Edimburgo 'Third Cinema: Theories and Practices' en 1986) y se favoreció la creación de colectivos, talleres y productoras independientes. La 'Workshop Declaration', un acuerdo comercial creado en 1982 entre el sindicato de directores (ACTT) y varias instituciones públicas (entre ellas Channel Four y el BFI), permitía que un grupo de mínimo cuatro miembros con una práctica integrada de trabajo se configurarse legalmente como colectivo y accediese a ayudas económicas. En ese mismo 1982 nace el 'Black Audio Film Collective' (BAFC: 1982-1998) con John Akomfrah, Lina Gopaul, Avril Johnson, Reece Auguiste, Trevor Mathison, Edward George y Claire Joseph (reemplazada en 1985 por David Lawson), seguido un año después por el 'Sankofa Film \& Video Collective' con Isaac Julien, Martina Attille, Maureen Blackwood, Nadine Marsh-Edwards y Robert Crusz. Mucho se ha escrito sobre estos colectivos (a los que hay que añadir el 'Ceddo' y 'ReTake') y su relación con sus predecesores afroamericanos de los 60s del 'Black Arts Movement' y con el movimiento audiovisual colectivo y experimental liderado por el teórico de cine Teshome Gabriel en la Universidad de California Los Ángeles bautizada por Clyde Tylor como 'L.A. Rebellion' (surgido asimismo como respuesta a las revueltas del barrio afroamericano de Watts en Los Ángeles en 1965)². Las experiencias vanguardistas radicales en lo formal y político de un grupo de afroamericanos y africanos, entre los que destacan Charles Burnett, Haile Gerima, Julie Dash y Arthur Jafa, servirían de referencia a sus seguidores británicos décadas después. De este diálogo continuado es ejemplar la amistad y colaboración entre John Akomfrah y el artista y cinematógrafo Arthur Jafa ${ }^{3}$, quien ha sido recientemente galardonado con el León de Oro en la Bienal de Venecia (2019) por su obra 'The White Album' (2018) ${ }^{4}$, incluida en la exposición central 'May You Live in Interesting Times'. Esta obra, así como su video-ensayo previo para la galería 'Love Is The Message, The Message is Death' (2016), se relaciona con las últimas propuestas de Julien y Akomfrah. Arthur Jafa define 'The White Album' como una pieza que «en igual medida, es ensayo, poema y retrato, y reflexiona sobre

2. Adhiriéndose a los postulados del Tercer Cine de impulso Latinoamericano (cuyo manifiesto firmarían Fernando Solanas y Octavio Getino en la revista 'Tricontinental' en 1969), este cine se oponía tanto al Primer cine de Hollywood (industria de entretenimiento) como al Segundo (cine de autor). Los postulados de un cine revolucionario en su formato colectivo, en su forma y en su marginalidad ante la industria cinematográfica; entendido como herramienta decolonial frente al capitalismo y su arma de entretenimiento amnésico -Hollywood-; y llamado a motivar a su público a la reflexión y la acción, fueron la inspiración para los miembros del 'L.A. Rebellion', quienes hicieron suyas sus reivindicaciones para enfrentarse al control y opresión racista de la población afroamericana y, a su vez, producir relatos íntimos y alternativos al de los medios de comunicación. El acto de traducción y adaptación de estas enseñanzas por el historiador de cine y teórico etíope Thesome Gabriel, profesor de UCLA, fue determinante en las primeras obras de Haile Gerima, Charles Burnett, Jamaa Fanaka, Billy Woodberry, o Julie Dash.

3. Nacido en Mississippi en 1960, Arthur Jafa ha trabajado durante décadas como director de fotografía de películas y vídeos musicales. Conocido por los vídeos de Solanges Knowles y Jay-Z, su trabajo tras la cámara ha ido definiendo una estética cinematográfica negra independiente. En esta línea: 'Daughters of the Dust' de Julie Dash (1991), primera película de una afroamericana distribuida comercialmente, e inspiración para 'Lemonade' de Beyonce (2016); 'Crooklyn', de Spike Lee (1994); 'Rouch in Reverse', de Manthia Diawara (1995) y 'Seven Songs for Malcolm X' (1993) del propio BAFC.

4. Título que toma como referente el álbum de los Beatles de 1968 y la obra literaria homónia de la novelista norteamericana Joan Didion (1979). 
el tema de la raza». En este video, sujeto a constantes re-ediciones y proyectado en bucle en galerías, el autor usa imágenes de fuentes diversas (grabaciones domésticas, vídeos de internet, testimonios, fragmentos de conciertos y apariciones de personalidades como Iggy Pop, O.J. Simpson o Erikah Badou) para reproducir el continuum mente-online actual, llamándonos a reflexionar sobre la "psicopatología" (Jafa) de los sujetos blancos desde elementos de una "estética negra" que no toma a la figura negra como sujeto ni aspira a la epifanía sino que parte de la hibridación, lo sincopado y el sampleado de la música negra. El filme critica un momento histórico cargado de violencia, al que contrapone retratos de amigos y familia, planteando como central nuestra capacidad de amar (C\&: 2019). Desde los años 90s, Arthur Jafa demuestra que es posible «hacer un cine negro con el poder, la belleza y la alienación de la música negra” (Jafa: 2019).

Tanto en BAFC como en 'Sankofa', la investigación y praxis proponían, en primer lugar, un correctivo a los regímenes de representación de las vidas negras en los medios de comunicación generales. La culpabilidad y deshumanización de los cuerpos negros, mostrada por la televisión durante las revueltas raciales de 1981 en el Reino Unido, demostró, para diversos colectivos negros, la urgencia de mostrar otras voces, historias y experiencias de una juventud inglesa diversa en lo racial, cultural y personal. Para esta labor, "la clase del 81'", formada en universidades e institutos politécnicos y armada con teorías derivadas del psicoanálisis, el post-estructuralismo, la sociología y los Estudios Culturales incipientes con Stuart Hall a la cabeza, era la idónea para plantear cuestiones no admisibles dentro de los círculos negros hasta la fecha. Su voz disidente dentro y fuera de las comunidades negras, con una producción que trasciende el mero «testimonio sobre las vidas negras" no sólo en lo estético sino en la fusión de temas culturales, políticos, ideológicos, de género, sexuales y económicos, los llevaría a una investigación ético-formal de reformulación de códigos fílmicos. Con un montaje audiovisual que seguía la lógica asociativa, la subjetividad, la intertextualidad y la reflexividad, voces, historias y mitos diversos eran llamados a dialogar incitando al espectador a reflexionar.

De la producción extensa de los primeros años de actividad de Julien y Akomfrah, me centraré en dos obras, clásicos del cine negro universal e incluidas en retrospectivas y ciclos cinematográficos por todo el planeta: 'Handsworth Songs' (1986) del BAFC y 'Looking for Langston' (1989) de Julien.

'Handsworth Songs' responde a la segunda gran ola de revuelta en ciudades británicas (septiembre de 1985). Realizada para la serie de Channel 4 'Britain: The Lie of the Land', obtuvo el Premio John Grierson del BFI al mejor documental, circulando por festivales internacionales. Evitando la voz-over autoral, 'Handsworth Songs' despliega técnicas ahora canónicas del cine-ensayo: superposición de capas narrativas, creación de un mosaico sonoro, constante experimentación visual y mezcla de archivos fílmicos y fotográficos con entrevistas contemporáneas. Este documental se nutría de las enseñanzas de grandes filósofos de la luz, el tiempo y el movimiento: los soviéticos Sergei Eisenstein; Dziga Vertov; Andrei Tarkovski, Alexander Rodchenko y Dovzhenko; los franceses Robert Bresson y Jean-Luc Godard y, sobre todo, del revolucionario ensayo fílmico 'Sans Soleil' de Chris Marker (1983). Partiendo de una compleja banda sonora de Trevor Mathison (colaborador de Akomfrah hasta la fecha) hecha de repeticiones, dilaciones y rupturas del sonido en sintonía con la música diaspórica del momento, 'Handsworth Songs' mezcla y superpone imágenes de archivos fotográficos, fílmicos y televisivos con declaraciones de personas participantes o testigos de las revueltas, 
así como de gente de las diversas comunidades de Handsworth. En el minuto 43 una mujer comenta: "There are no stories in the riots, only the ghosts of other stories». Esta frase, repetida, puede considerarse el manifiesto fílmico de BAFC, que propone frente a la "narrativa maestra" de la historia en singular un mosaico de historias guiadas por el ejercicio de la memoria afectiva, donde encontramos, entre las fallas de lo legible y lo ilegible, huellas fantasmales de historias vividas. El grupo disputaba la supuesta neutralidad ideológica del audiovisual, planteando cuestiones sobre la representación negra, el colonialismo y las sociedades diaspóricas.

Cuando se presentó esta obra, a mediados de los 80s, todavía no se vislumbraba en el horizonte el papel que vendría a ocupar el ensayo fílmico en la práctica y crítica audiovisual radical entre mujeres, la comunidad LGBTI+ y los artistas de color. Apunta Paul Arthur:

[T] he majority of essays cast themselves as oppositional, interrogating received wisdom or status quo ideologies from left perspectives. Further, a significant number of women (Agnès Varda, Yvonne Rainer, Jill Godmilow, Ngozi Onwurah) and artists of color (Marlon Riggs, Patricio Guzmán, John Akomfrah, Raoul Peck) have adopted the essay as an instrument of creative struggle (Alter, 2017, p.164).

Formado en Saint Martin's School of Art, los referentes cinematográficos de Isaac Julien se vieron ampliados en los años de 'Sankofa' por su asistencia a talleres negros. Si hasta el momento se había fijado en aspectos formales, poéticos y políticos de los directores de la GPO Film Unit británica (Humphrey Jennings, Alberto Calvacanti, Harry Watt y Basil Wright), el exponerse a 'Les statues meurent aussi' (1953) y 'Sans Soleil' (1983) de Chris Marker; 'Hipótesis del cuadro robado' (1977) de Raoul Ruiz y 'Reassemblage' (1982) de Trinh T. Minh-ha le mostraron otros caminos posibles. Julien:

Marker's films pointed to a form of ethnography that was critical but also personal and poetic. By taking the experimental-film form and contextualizing it within the film-essay genre, 'Sans Soleil' provided a model for how to bridge the two distinct filmmaking traditions of experimental film and political essayist documentary. It wasn't just neo-formalism. That, I think, has always been my problem with abstract film: that, in formal terms, it might be radical and interesting, but it was never radical enough in terms of content. (Alter, 2017, p. 335).

Esta mezcla de lo radical en el contenido y la forma sin recurrir a la abstracción ha guiado toda su trayectoria. La película que lo daría a conocer a finales de la década, 'Looking for Langston' (1989), es un film-manifiesto del deseo gay negro, una declaración de motivos personales y un homenaje a sus maestros desde los créditos de apertura. Como una película muda, en un texto blanco sobre pantalla negra con ribetes leemos: «Una meditación sobre Langston Hughes y el Renacimiento de Harlem», "con la poesía de Essex Hempill y Bruce Nugent» y "en memoria de James Baldwin". Filmada en blanco y negro y producida por 'Sankofa', sus 42 minutos representan una meditación poética del deseo homosexual durante el Renacimiento de Harlem. La banda sonora está compuesta por un recitado de poemas de poetas negros gay, lecturas dramatizadas y música lírica. Hay tanto imágenes de archivo (fotografía y celuloide) como escenas originales. El archivo reúne grabaciones y fotografías de Langston Hughes y de sus coetáneos Countee Cullen, Alain Locke, Bruce Nugent y Wallace Thurman (el grupúsculo gay del movimiento); escenas ya icónicas del Harlem 
de los años 20s (el tren elevado, gente paseando por la 125st, las exposiciones de arte del "New Negro" promovidas por Locke); obras fotográficas de artistas como Carl Van Der Zee y Roy DeCarava y, finalmente, un par de fotografías de James Baldwin, poeta y activista gay que, marginado por su orientación sexual, ha sido revisado y reconocido a nivel internacional en los últimos años ${ }^{5}$. El metraje original de Isaac se intercala entre materiales de archivo para recrear el amor y la muerte entre la comunidad homosexual con tres escenas: el funeral de Hughes (con Isaac en el féretro), una escena onírica surreal de amor de una pareja interracial, y una fiesta homosexual en una especie de 'speakeasy' disuelto por una brigada policial. El lirismo y la búsqueda de la belleza, algo de lo que no ha prescindido Julien en toda su carrera, bebe de la estética del Renacimiento de Harlem y, en concreto, de dos ensayos visuales en papel: The Sweet Flypaper of Life (1955) y The Harlem Book of the Dead (1978), ambos en blanco y negro. The Sweet Fypaper of Life incluye fotografías de Roy DeCarava sobre la vida en Harlem en los años 40 y 50 pero excede su papel de documentación por su alta creatividad, acentuada por el texto poético que Langston Hughes escribió como elemento estructural y evocador entre las imágenes. The Harlem Book of the Dead (1978), por su parte, reúne fotografías de funerales tomadas por Carl Van Der Zee en la primera mitad del siglo XX. El volumen fue editado por la artista y coleccionista de arte negro Camille Billops, con introducción de Toni Morrison y con una larga entrevista entre Billops y Van Der Zee intercalada entre fotos de exequias retocadas. El libro nos invita a adentrarnos en un momento de la historia y la cultura negra estadounidense donde la muerte se asoma constantemente, con unas fotografías donde imágenes y textos bíblicos se superponen a las instantáneas de los muertos, tal como hará en sus series de los años 90s el pintor afroamericano Kerry James Marshall. La tensión entre lo individual y lo colectivo, lo poético y lo político, la conversación entre el texto escrito y las imágenes, y la búsqueda de referentes estéticos negros fueron razones determinantes para que Julien acudiese a estas obras.

El intelectual, profesor e historiador afroamericano Henry Louis Gates Jr. apunta con perspicacia elementos del método de trabajo y filosofía en los que Julien seguirá profundizando:

That 'Looking for Langston' is in part a meditation on the Harlem Renaissance is, I think, no accident. For the evocation of the historical Harlem Renaissance is, among other things, a self-reflexive gesture, meant to establish a relation between it and London's black British cinema of the 1980s. To put it crudely, we look for Langston, but we discover Isaac. And yet the historical quest is clearly for affinities, not roots. This is, self-consciously, a search for a usable past. Thus, a film like 'Looking for Langston' must be read, too, as a response to the homophobia of black nationalism, one that proceeds by constructing a counter-history in which desire and mourning and identity can interact in their full complexity (Gates, 1992: 26.)

En efecto, Julien se sirve de la historia y antecedentes negros gays para la reconstrucción de una historia alternativa sobre el Renacimiento de Harlem, a la vez que crea conexiones entre el pasado neoyorquino y su presente londinense. El archivo y

5. Sirva como ejemplo la película 'I Am Not Your Negro' (2016) de Raoul Peck, su personal homenaje sobre el papel que los escritos y la vida de James Baldwin tuvieron en toda una generación diaspórica negra en busca de referentes. 
la revalorización de clásicos negros sirven a la investigación íntima sobre los mecanismos de representación del deseo, el luto y la identidad que fluye entre obras de pintura, fotografía, poesía, cine y danza. Sin limitarse a referentes negros, el recurso a la historia del arte y la investigación sopesada, serán aspectos que Julien perseguirá en obras futuras, cuando se convertirá en "coreógrafo" de sus obras multipantalla.

Poco después de 'Looking for Langston', Julien alcanzaría amplio reconocimiento con 'Young Soul Rebels' (1991), premio de la crítica en Cannes. En el diario sobre la producción de la película, coeditado por Issac Julien y Colin McCabe para el BFI, encontramos esta frase de Hall en portada: "Young Soul Rebels' opens a new era in black British film-making - this is the story of how, against all the odds, it got made» (Julien y MacCabe, 1991, portada). Con el objetivo de dar a conocer a públicos más amplios las experiencias de jóvenes 'soul' londinenses en 1977, 'Young Soul Rebels' (un complejo ejercicio de coproducción y búsqueda de financiación), demostró el interés de espectadores y crítica por historias diferentes en la gran pantalla. Siguiendo la estela del éxito de Stephen Frears en 1985 con 'My Beautiful Laundrette' (guion de Hanif Kureishi), la película de Juien tuvo muy buena acogida. Sin embargo, el gran esfuerzo y dedicación para hacer una "ficción tradicional", llevó a que Julien se centrase desde entonces en la galería y el museo, asomándose puntualmente al documental de cine y televisión. Destacan entre estas: 'Frantz Fanon: Black Skin, White Mask's, 1995, sobre Frantz Fanon, personaje icónico de la filosofía y lucha postcolonial; 'Baadassss Cinema', 2002, clásico sobre las contradicciones políticas y materiales del cine 'Blaxploitation' afroamericano y, por último, acompañado por Tilda Swinton, el documental experimental 'Derek' (2008), un poético y evocador panegírico sobre su amigo Derek Jarman.

El deambular fílmico entre imágenes, narrativas y sonidos de 'Handsworth Songs' y 'Looking for Langston' apuntaban ya, visto desde la distancia, a una transición a la galería por su radicalidad en el contenido y la forma; por su urgencia en responder a cuestiones del presente recurriendo al archivo y a la investigación sobre el pasado, y por su interés por conquistar espacios no transitados por artistas negros situando lo sonoro en primer plano. Su movimiento al cubo blanco lo aceleraría el advenimiento de la digital, la cual, al rebajar los costes de filmación, permitió desarrollar la experimentación multipantalla.

\section{Paradojas y efectos de la crisis}

A estos años formativos, en los que Akomfrah y Julien van fijando elementos de su praxis y filosofía mientras aprenden el funcionamiento del mercado del arte y la industria cinematográfica, se suceden décadas en las que realizan obras que se mueven entre la galería, la academia y la televisión, afianzando alianzas personales, marcando sus referentes político-estéticos y manteniendo su colaboración con miembros de los colectivos disueltos. Julien trabaja con Mark Nash y una miríada de colaboradores que se entrecruzan entre sus obras, mientras Akomfrah convirtió el BAFC en la productora 'Smoking Dogs' en 1997 con otros dos miembros del BAFC: Lina Gopaul y David Lawson (productores), a quien se une frecuentemente Trevor Mathison, compositor de los complejos paisajes sonoros de sus obras.

Una serie de hechos histórico-institucionales interrelacionados explican su reconocimiento como autores, motivados en buena medida por cambios en el interés de 
la institución artística por temas, artistas y obras nuevos a raíz de la crisis financiera reciente. Este tsunami global tendría como efecto el revalorizar el coleccionismo artístico (espacio más seguro de inversión) y que museos, comisarios y galerías atendiesen a temas antes marginales como la emigración, el desplazamiento forzado, la crisis ecológico-humanitaria, los efectos de la historia colonial y racial del capitalismo en el presente, y la condición generalizada del contemporáneo del ser humano como sujeto disperso, descentrado y fragmentado. Estos temas y experiencias eran ya centrales en obras de artistas negros diaspóricos, pero el inusitado interés de occidente (un occidente que cierra fronteras y endurece políticas migratorias mientras organiza retrospectivas artísticas que denuncian tales hechos) situó en primer plano a Akomfrah y Julien. Nuevos conocimientos histórico-teóricos basados en investigaciones y publicaciones académicas en los EE.UU. y el Reino Unido colaboraron en situarlos en un lugar señalado en la historia del arte y creación negras. Desde los años 2010, la recepción positiva en museos, festivales y galerías occidentales de exposiciones sobre artistas negros responde por tanto a los efectos directos de la crisis del 2007-8, al papel legitimador de la academia y, por último, al surgimiento de comisarios estrella africanos en la diáspora como Okwui Enwezor, Simon Njami o Koyo Kouh, quienes ofrecieron el 'know-how' para exposiciones más allá de Europa sobre estos temas y artistas. Las conexiones discursivas y personales de Akomfrah y Julien con estas figuras ha sido determinante en su estatus. A su favor tienen, además, el "giro documental» en la historia y crítica de arte, interesado en descubrir materiales de archivo no occidentales con conocimientos, propuestas y actores de los márgenes.

Como resultado de estos cambios, el apoyo de instituciones y actores culturales les ha permitido una mayor libertad creativa al acceder fácilmente a fondos de producción. Conscientes de las vicisitudes del mundo del arte contemporáneo, ambos artistas mantienen gran control del discurso sobre su producción y su figura autoral. Mostraré ahora un conjunto de hechos que demuestra la sincronía entre obras, mundo artístico y respuesta de estos autores en la última década.

Julien presentó en la Bienal de Venecia de 2010 'Ten Thousand Waves', una instalación fruto de cuatro años de trabajo. Filmada entre China e Inglaterra y proyectada sobre nueve pantallas de doble cara, combina mito, arte e historia para examinar las relaciones de la emigración global motivada por el capital. En 2013-4 el MoMA la presentó en su sala central con una retrospectiva dedicada a sus obras fílmicas. El catálogo adjunto (Riot, 2013) es un texto esencial para acercarse al artista. A diferencia de catálogos razonados al uso con biografía, imágenes de obras y textos críticos, Riot es una biografía intelectual ilustrada en la cual el artista relata encuentros, momentos formativos y anécdotas vitales. Fotos, polaroids y fotogramas acompañan los escritos de Isaac, de su pareja y colaborador Mark Nash, y de escritores y críticos como Paul Gilroy, bell hooks, Kobena Mercer, Laura Mulvey y Stuart Hall. Estos colegas, mentores y confidentes completan la biografía más comprensiva de la obra del artista hasta la fecha. El año siguiente, Julien participaría en la mítica $56^{\mathrm{a}}$ Bienal de Venecia, dirigida por el comisario nigeriano recientemente fallecido Okwui Enwezor, con un tríptico sobre el capital que ocupará la sección final de este artículo.

En plena crisis en el 2007 se presentó en FACT (Foundation for Art and Creative Technology, Liverpool) la esperada exposición retrospectiva del BAFC. Los comisarios eran 'The Otolith Group', colectivo negro británico compuesto por Kodwo Eshun y Anjalika Sagar, quienes habían estado en diálogo directo con Akomfrah durante años. Junto a la muestra se editó The Ghosts of Songs: The Art of the Black 
Audio Film Collective, con diseño del arquitecto anglo-ghanés David Adjaye y textos de los integrantes de BAFC. A estos se añadían artículos ya clásicos de Jean Fisher, Kobena Mercer y Okwui Enwezor, Volumen de peso (real y simbólico) es la obra-manifiesto crítica del colectivo y una página a pasar para que Akomfrah fuese reconocido de manera independiente. Su éxito se vislumbraba cuando el MoMA compró la obra multicanal sobre Stuart Hall 'The Unfinished Conversation' (2012). Hasta ese momento, Akomfrah había trabajado sin pausa realizando documentales para televisión y obras independientes donde se ocupó de historias no contadas a través de momentos históricos, narrativas de sujetos marginados y personalidades sepultadas del siglo XX. Le interesaron los héroes afroamericanos Malcolm X ('Seven Songs for Malcolm X', 1993) y Martin Luther King ('Martin Luther King: Days of Hope', 1997); la Marcha a Washington de 1963 pro-Derechos Civiles ('The March', 2013) y las revueltas de Liverpool en 1981 ('Riot', 1999), así como aspectos esenciales de la estética negra, destacando el clásico sobre el afro-futurimo 'The Last Angel of History', 1996. En 2013, el desdoblamiento del proyecto sobre Stuart Hall en una obra mono canal ('The Stuart Hall Project') y el multicanal citada, abrirá nuevas posibilidades facilitadas por su alianza con la londinense Lisson Gallery. Ambas obras son ensayos sónico-visuales íntimos donde se retrata la vida, la obra y el contexto que rodeó al teórico cultural poscolonial Stuart Hall, abriendo nuevas reflexiones sobre historias y cambios determinantes del siglo XX relegados al margen. Sirviéndose de su característica manipulación del archivo, intertextualidad, contraposición de fuentes y un cuidado extremo por lo sonoro, Akomfrah entreteje narrativas políticas del siglo pasado e historias íntimas a través de un metraje recabado en su labor de archivista, puntuado por imágenes nuevas (fotografías familiares entre los árboles de un bosque, bañadas por un riachuelo o el mar) que funcionan como hilo emocional de la obra. La arqueología sonora de Miles Davis, músico predilecto de Hall, es determinante como mapa de una era, aludiendo a la identidad fragmentada del sujeto diaspórico, esa "conversación inacabada" de Hall. Ambas (una dirigida al cine y la otra al museo-galería), puestas en conversación o bien de manera independiente, abrieron al artista nuevos espacios del mundo del arte. La capacidad de adaptación (compartida por Julien) de obras al espacio, el presupuesto o la filosofía del programa expositivo permite una circulación e impacto mayores. En obras sucesivas, ambos autores suelen partir de la obra primigenia multipantalla, para proceder posteriormente a reducir las pantallas o proyectarla como monocal. De este modo, cuestionan el concepto clásico de la obra inmutable, final e inalterable (como Jafa con su edición constante) y demuestran la necesaria maleabilidad y negociación del sujeto en el siglo XXI.

En 2015 Akomfrah presentó 'Vertigo Sea' en la Bienal de Venecia de Enwezor, donde exploraba la relación de tensión entre el hombre y al mar, llegándole poco después la consagración internacional con el premio Artes Mundi en su $7^{\mathrm{a}}$ edición ${ }^{6}$ por su labor de artista visual «comprometido con la condición humana, la realidad social y experiencias de vida”. Sus obras más recientes ('Vertigo Sea', 'Tropikos' y 'Auto da fé', 2015-6) se podrían concebir (en aras de una necesaria simplificación) como un tríptico que usa el formato multipantalla y textos, archivos y fuentes visuales diversas para reflexionar sobre el papel del mar en las migraciones históricas y desplazamientos

6. En la edición anterior Artes Mundi había premiado al artista multidisciplinario afroamericano Theaster Gates. 
poblacionales forzadas por cuestiones religiosas, racistas y/o económicas. Igualmente, presenta el océano como lugar intermedio (ese "pasaje intermedio» del Atlántico negro de Paul Gilroy) entre tiempos y espacios, y como elemento de reflexión artística central en la estética romántica. Nótese el elemento acuático (poético, conector, global e histórico), común a 'Ten Thousand Waves'.

Tras su afianzamiento en el mundo del arte, ambos autores fueron reconocidos por la crítica y teoría cinematográficas, un hecho que, hasta el momento, había sido negado a cineastas negros. Encontramos sus nombres en diversas publicaciones sobre el cine-ensayo e, incluso, tienen un capítulo en un volumen sobre películas del ártico (Films on Ice. Cinema of the Artic). Gracias a la sanción conjunta de crítica e institución, Julien y Akomfrah no han dejado de recibir encargos, transitando entre formatos, problemas teóricos y espacios más allá de lo africano o lo negro, centrándose en el formato multipantalla acogido en museos, galerías y centros de arte experimental. El interés por proyectar en salas de cine o televisión en sus primeros años se ha visto desplazado por el cubo blanco.

Hasta llegar a esta posición de libertad creativa, Akomfrah y Julien han compartido una característica esencial: su versatilidad para situarse en relación de conexión e independencia fluctuante con el mundo del arte y la cultura negros. El centro de irradiación de «lo negro» en el arte está, en primer lugar, en la población negra estadounidense y su lucha desde inicios del siglo XX por acceder a los medios de producción de la cultura popular y del arte. Los logros se han materializado a lo largo del siglo XX en una presencia creciente de obras de artistas negros en museos, galerías y pantallas, lográndose en su plenitud en la actualidad, en buena medida por el trabajo de redes globales, donde comisarios, críticos y artistas africanos y diaspóricos trabajan en conjunto. Hombres y mujeres negros, africanos y diaspóricos, ocupan el museo (la keniana Wangechi Mutu afincada en Nueva York acaba de decorar la fachada del MET de NYC), filman películas independientes como 'Moonlight' (Barry Jenkins, 2016) que barrió en los Premios Óscar, y comerciales como el taquillazo de Marvel 'Black Panther' (Ryan Coogler, 2018) o 'Selma' (2014) de Ava DuVernay. Esta directora y productora es ejemplar en su habilidad para tratar temas históricos y contemporáneos candentes de la comunidad negra y convertirlos en éxitos instantáneos, sean estos documentales o series de ficción a través del dominio del lenguaje cinematográfico "clásico" ('13th', 2016; 'Queen Sugar', 2016; 'When They See Us', 2019). Entre la abundancia de obras de realizadores negros destaca la comedia creada por Issa Rae en 2016 para el canal privado HBO 'Insecure' (ya en su $4^{\mathrm{a}}$ temporada) demostrando la curiosidad por historias, sensibilidades y voces negras no marcadas por «la carga de la representación» de la comunidad. Este interés internacional por el audiovisual negro ha provocado que plataformas digitales de streaming online como Hulu, Amazon Prime o Netflix compren obras de directores negros y produzcan contenidos originales desde África y la diáspora.

A este movimiento de conquista de la población afro-americana del panorama audiovisual 'mainstream', se añade la polifonía de voces internacionales en congresos, festivales y cursos universitarios que debaten sobre aspectos conectados al aumento de legitimidad de la creación negra: la ausencia y errores de la representación del cuerpo negro en la historia del arte y la cultura popular; la existencia o no de una 
"estética negra»; la centralidad de la condición negra como ejemplo de identidad fluida y fragmentada, y la necesidad de restitución de obras de arte africanas saqueadas durante la colonización (con Felwine Sarr y Bénédicte Savoy a la cabeza tras su estudio para François Macron). Cuando importantes instituciones han asumido la obligación de tratar estos temas, ya transitados en profundidad desde los márgenes más radicales, Akomfrah y Julien han dado un giro hacia temas de alcance mayor, centrándose en crisis que consideran más apremiantes.

People assume that there are certain transcendental duties that Black filmmaking must perform. They assume that and because of that Black filmmaking must work with the understanding that it's in a state of emergence. And because it is in a state of emergence its means always must be guerilla means, war means, signposts of urgency. When that begins to inhibit questions of reflection -doubt, skepticism, intimacy and so on- then the categorical imperative does exactly what it is supposed to do- it imprisons. (Akomfrah, 2013).

'Purple', de Akomfrah y el tríptico sobre el capital de Julien son sus respuestas a los efectos de la crisis del 2007-8 y a nuestra condición contemporánea. Con ellas se sitúan en un lugar diferente al de otros creadores negros, convirtiéndose en "catalizadores» o conectores en una cadena histórica de arte y activismo panafricano internacionalista. Como eslabones de esta cadena, invitan al público a dialogar con creadores y pensadores negros mientras reflexionan sobre cuestiones históricas globales. Ambos autores, por la tensión entre la historia personal y la colectiva, se han regido por la siguiente máxima fanoniana, recogida en su texto Les Damnés de la Terre: "Chaque génération doit, dans une relative opacité, trouver sa mission, la remplir ou la trahir». (Fanon, 2002, p.199).

'Playtime' será el centro de mi análisis, desde donde apuntaré algunos elementos comunes con 'Purple' para finalizar reflexionando sobre la presencia de la obra 'Four Nocturnes' de Akomfrah en la última Bienal de Venecia (2019).

'Playtime' (2013-4) de Isaac Julien se presentó en la galería londinense Victoria Miró como instalación audiovisual de 7 pantallas, acompañada por fotografías de gran formato. Con ella, el artista quería responder a una pregunta que le corroía: «ipor qué es tan difícil representar el capital?». Primero se trataba de identificar las características contemporáneas del capitalismo global y luego abordar el problema de cómo visualizar tal abstracción. El proceso de investigación de la obra comenzó en 2012 cuando Julien invitó a su amigo, el filósofo marxista David Harvey, a dialogar sobre la sociedad capitalista global en el "Wide Open School», un proyecto de la Hayward Gallery centrado en performances de artistas. Al evento asistieron Stuart Hall y otros pensadores, y la conversación se centró en cómo la crisis había hecho que, cada uno de nosotros, notásemos los efectos del capital ("como la gravedad", que diría Harvey) aunque se nos escapase cómo representarlo. La velocidad, el flujo y la búsqueda del beneficio característicos del capital, surgieron como aspectos centrales de aquella conversación. En 2015, titulada 'Kapital' y convertida en una proyección de dos pantallas, viajaría a la Bienal de Venecia para dialogar con su hermana mayor: 'Playtime'. De

7. Algo que Alain Locke ya pusiera sobre la mesa durante los años 20 durante la «Harlem Renaissance» $\mathrm{y}$ "The New Negro", reformulado en décadas posteriores por diversos pensadores, artistas y teóricos como Amiri Baraka, Kobena Mercer, Glenn Ligon, Greg Tate o Fred Moten. 
manera paralela, Julien se había embarcado en la exploración de tentativas previas de representación del capital en la historia del arte, topándose con las litografías del húngaro Hugo Gellert del Capital en 1933 y con el intento fallido de Eisenstein en cine, retomado por Alexander Kluge. Tras esta investigación optaría por representar los efectos del capital a través de seis relatos basados en personas que conocía, corrigiendo a Marx con una visión del proletariado con componentes raciales, sexuales y de género.

'Playtime' toma su título de la película homónima francesa de 1967 de Jacques Tati. La instalación de siete pantallas HD y sonido envolvente 7.1 comparte con el clásico de Tati una bella coreografía visual, el cuidado compositivo de planos y un montaje ágil a ritmo de jazz, que atrapa y seduce al espectador, forzado a enfrentarse a los efectos de este juego del capitalismo global ("It's a game», nos interpela James Franco como asesor artístico). Las dos películas sitúan a sus autores en el centro y se enfrentan a la disyuntiva de cómo representar los efectos alienantes del capital en sendos momentos históricos en los que las nuevas tecnologías revolucionaron las posibilidades de conexión humana. Las seis historias independientes que componen la pieza se ubican en Londres, Dubái y Reikiavik; ciudades centrales del capital (Londres, una ciudad transformada por desregulación de los bancos; Reikiavik, donde empezó la última crisis y Dubái, un mercado en alza de Oriente Medio). Basadas en experiencias personales de los propios actores o conectadas con sus vidas, los relatos muestran a personajes arquetípicos interconectados, definidos únicamente por su profesión y afectados directamente por la crisis y el flujo del capital: el «hedge fund manager", el artista, el marchante de arte, la periodista, el asesor de arte y la trabajadora doméstica filipina en Dubái. La hora larga de metraje de 'Playtime' muestra sin concesiones la dependencia absoluta del mundo del arte del capital global provocando una conversación transnacional sobre quién gestiona el mundo del arte y del capital financiero global (hombres blancos occidentales o negros) mientras el artista finlandés (en bancarrota) y dos mujeres (la periodista asiática y la doméstica filipina) se han de adaptar a la variabilidad de sus efectos y a sus flujos. La proyección simultánea de las seis historias (dependiendo del espacio expositivo las pantallas se colocan en círculo o de manera contigua en un muro $^{8}$ ) permite al espectador transitar entre ellas de la mano de personajes aislados en sus espacios. El espectador se deja guiar por un montaje sincopado, deambulando a su antojo entre la hipnótica belleza del tráfico nocturno de metrópolis globales desde el lof de un rascacielos; exaltándose ante la frenética actividad de los parquets de los mercados de Oriente Medio; acompañando a la doméstica filipina entre las dunas del desierto, o admirando con fascinación las vistas del paisaje de lava islandés desde una mansión abandonada. Las sensaciones de seducción, subida de adrenalina, éxtasis estético, miedo a la soledad y alienación reflejan las que la búsqueda incansable de beneficio provoca en nuestras vidas. La experiencia de inmersión audiovisual multipantalla, los colores saturados, los cuadros de estirpe romántica y un paisaje sonoro envolvente, demuestra cómo la fusión de estrategias visuales y narrativas clásicas multiplicadas y contrapuestas puede ser un lenguaje más apto que el escrito para enfrentarse a la representación del funcionamiento y efectos capital. Cuando las herramientas del lenguaje escrito se

8. En galerías, museos y centros de arte con limitaciones espaciales y/o económicas, Julien ha presentado la obra en sólo tres pantallas o como vídeo monocanal. 
quedan cortas, el lenguaje audiovisual llega para completar y dialogar con él. En un ejercicio de introspección, Julien se circunscribe al mundo del arte que conoce y al que pertenece, situándose en el centro de la reflexión con la propia materialidad de la obra: producir, distribuir y proyectar una obra así es factible únicamente para grandes galerías e instituciones. Julien, quien había abandonado el mundo del cine independiente hacía décadas, cuestiona y muestra la connivencia del arte contemporáneo con el capital.

Estas vidas entrelazadas a través de esta "coreografía audiovisual del capital» encontraron apoyo teórico cuando la obra se presentó dentro de la $56^{\mathrm{a}}$ edición de la Bienal de Venecia "All the World's Futures». Además de recuperar la conversación con Harvey de 2012 ('Kapital') en dos pantallas, se completó el marco intelectual del proyecto con la sonorización de El Capital. Crítica de la economía política (Karl Marx, 1867). Titulado 'Das Kapital Oratorio' y solicitado por Enwezor, la obra supuso la lectura comprensiva y continuada del tratado de Marx. Durante los meses que duró la $56^{\mathrm{a}}$ edición de la Bienal de Venecia, doce actores acudieron por turnos a la ARENA, lugar de encuentro diseñado por David Adjaye. La omnipresencia del capital se materializó en este oratorio inusitado en suelo veneciano.

Sobre 'Purple', de Akomfrah (2017, todavía en circulación internacional en 2019 y su respuesta personal al antropoceno), apuntaré un conjunto de elementos relacionados con 'Playtime'. Tuve la ocasión de ver la obra de seis pantallas HD con sonido 7.1. en su presentación española como actividad paralela de ARCO 2018 en el Thyssen-Bornemisza (Madrid). Primera obra encargada por el Museo y la Thyssen-Bornemisza Art Contemporary (TBA21), 'Purple' formaba parte de los actos conmemorativos del 25 aniversario del museo. En esta obra multipantalla, el artista investiga otra emergencia contemporánea derivada y ligada al capital: el cambio climático y sus efectos, a la vez que desmiente la idea de progreso humano. Emplea con este fin una ingente cantidad de imágenes de archivo de la BBC y parte de su archivo visual personal, haciéndonos recorrer momentos determinantes del siglo XX y XXI que han provocado fenómenos climáticos extremos, la desaparición de especies y el inexorable aumento del nivel del mar. Tales efectos han sido filmados durante viajes recientes del artista pagados por la TAB21-Academy con su estética romántico-sublime característica. El paisaje sonoro de múltiples capas de Trevor Mathison permite casi infinitas permutaciones en el visionado de unas imágenes organizadas a través de trece sugerentes títulos y seis movimientos, a modo de capítulos de un libro. La maestría en el momento del montaje, en base a lo que el autor denomina "proximidad afectiva" de imágenes y sonidos, crea múltiples lecturas para el espectador. Este ensayo elegíaco sobre un mundo perdido hace reflexionar desde el título: 'Purple'. Como ha comentado Akomfrah en entrevistas, el púrpura es un color que no se encuentra apenas en la naturaleza, con características híbridas (azul y rojo) y alude a lo intermedio y a la pérdida, como color del luto en Ghana.

Tanto las imágenes de Julien como las de Akomfrah remiten a la belleza romántica y radiante de la pintura victoriana, un gesto que escapa tanto del brutalismo moderno como de la fealdad de lo accesible y popular del mundo fragmentado digital. Apunta T. J. Demos sobre Vertigo Sea: "showing us the unparalleled splendour of aquatic nature; this is, as well, a courageous act of refusing the contemporary cynicism that has given up on beauty, even while it rightfully sees beauty itself as threated, if not colonized, by consumerist spectacle» (Ballard, 2018, p.79). Incluida en la Bienal de Venecia de 2015, su presencia tuvo sin duda un efecto favorecedor para que, en 2017, obtuviese el 
premio Artes Mundi. Enwezor convocó, en respuesta y diálogo con el mercado global del, a un conjunto de artistas africanos y de otros «márgenes de Occidente», y muchos aprovecharon tal legitimidad para dar alas a su carrera. Sólo en este 2019, Julien ha representado dos obras: sobre el abolicionista afroamericano Frederick Douglass y sobre la arquitecta italo-brasileña Lina Bo Bardi. Akomfrah tiene actualmente en circulación producciones multipantalla sobre el "creador» del jazz en Nueva Orleáns Charles "Buddy» Bolden ('Precarity'), sobre la participación de soldados africanos y afroamericanos en conflictos bélicos del siglo XX ('Mimesis: African Soldier') y ha formado parte de la última edición de la Bienal de Venecia.

\section{A modo de coda}

En el primer pabellón nacional de la historia presentado por Ghana en la Bienal de Venecia (2019), titulado 'Ghana Freedom' (famosa canción de la independencia de 1957) y comisariado por la historiadora de arte y escritora Nana Oforiatta Ayim, la proyección de tres canales de John Akomfrah -'Four Nocturnes'- comparte el espacio creado en el Arsenal por el arquitecto David Adjaye con artistas de diversas generaciones de Ghana y la diáspora: Felicia Abban, El Anatsui, Ibrahim Mahama, Selasi Awusi Sosu y Lynette Yiadom-Boakye. Con sus característico lirismo y lucidez, Akomfrah ha definido el pabellón y su contenido como «un ejemplo carismático en un mar de testigos ". 'Four Nocturnes' evita celebrar éxitos nacionales, aprovechando la oportunidad para desenfundar su ingente colección de imágenes, recabadas durante años en archivos públicos y privados y mezclándolas con filmación original altamente compuesta a modo de «tableux vivants» románticos (algo habitual en sus obras desde hace un lustro) y mostrarnos su dominio del lenguaje audiovisual creando conexiones inesperadas en esa "proximidad afectiva" del montaje. En las tres pantallas se yuxtaponen episodios de violencia del occidente africano: del genocidio alemán del pueblo herero a la masacre contemporánea de elefantes. El público es invitado a participar en una conversación histórica global, contextualizando de otro modo asuntos contemporáneos y proponiendo lecturas alternativas forzándole a cuestionar la factura y el poder de atracción de las imágenes.

La contradictoria presencia de esta obra en el pabellón nacional de Ghana no pasó inadvertida al propio autor, quien comentaría: «la inconveniente etiqueta del pabellón nacional puede ser útil para atraer al público e implicarlo en una conversación posnacional más amplia sobre la importancia de no fijar de manera rígida las fronteras entre países africanos. El proyecto de las independencias no se centraba sólo en la autonomía política sino en la habilidad de crear un lenguaje de práctica cultural e identidad, lo que implica conversar con el exterior ${ }^{10}$.

Hasta ser celebrado como artista de Ghana en la cumbre del arte contemporáneo institucionalizado, Akomfrah ha vagado por mares y océanos (siguiendo la metáfora acuática apuntada) y recorrido paisajes terrestres en un constante movimiento de entrecruzamiento de ideas, formas y plataformas (del cine experimental y activista al documental de televisión hasta llegar al museo, las galerías y las bienales). Cuando

9. https://www.theguardian.com/artanddesign/2019/may/08/ghana-first-pavilion-venice-art-biennale-david-adjaye-ghanaian-artists-john-akomfrah

10. https://edition.cnn.com/style/article/ghana-venice-biennale-2019/index.html 
la inmensa mayoría de la población africana tiene, de facto, un pasaporte inútil, su capacidad para desplazarse como actor destacado desde la diáspora negra, conectando memorias e historias en sus obras, fuerza al espectador a reflexionar sobre las contradicciones del proyecto progresista de la modernidad occidental en un planeta dramáticamente amenazado por las actuaciones extractivas y megalómanas del ser humano, empeñado en negar su mortalidad y evitar su responsabilidad.

\section{Conclusión}

En la situación de emergencia global contemporánea, las obras de Akomfrah y Julien han sido recuperadas como pioneros de una reflexión artística situada ahora en el centro por la "crisis» migratoria global y su impacto en Europa con dos imágenes centrales: el Mediterráneo como frontera, lugar de tránsito y cementerio, y el retornado ultranacionalismo conservador con el Brexit a la cabeza.

Las cuestiones sobre el nacionalismo cultural negro internacional, la estética negra, la representación, las cuotas étnicas o raciales, la pluralidad y la identidad están siendo revisadas por las instituciones al resonar con fuerza entre la juventud afro-europea. Es aquí donde los colectivos negros de los 80 y, especialmente, las reflexiones y producción de Akomfrah y Julien aparecen como referentes destacados. Suyas son reflexiones sobre la relación europea con el concepto de raza, el papel de la historia, la memoria y las historias alternativas a lo largo de su carrera, así como las posibles limitaciones del lenguaje del cine clásico para subvertir la realidad de desigualdad e injusticia de poblaciones marginadas en las urbes europeas contemporáneas. Sin embargo, ninguno de ellos se ha limitado a estos problemas sino que sus propuestas filosóficas y obras aspiran a transformar nuestra manera de aprehender y percibir la realidad. Comenta Julien: «As an artist, I am interested in how philosophy and political theory can contribute to the understanding of culture and aesthetics, which, in turn, plays an essential role in the creation of new forms of perception" (Alter, 2017, p.343). En menos de medio siglo y por una legión de razones interconectadas, estos intelectuales han alcanzado una posición única desde donde crear, cuestionar y proponer sentido por su acceso privilegiado a instituciones y recursos. En sus últimas obras para el museo y la galería han planteado cuestiones candentes de la contemporaneidad a través de la lógica asociativa, la subjetividad, la heterogeneidad y la reflexividad, hoy de moda dentro de los círculos artísticos de comisarios y pensadores a través del ensayo fílmico, el archivo y la investigación como proceso de creación artística.

La complejidad, riqueza discursiva y belleza de sus últimas convierte en casi fútil el acto de traducción de la crítica, devolviendo una autonomía total a la obra, demostrando cómo el acto radical de expresión y resistencia frente a los flujos globales de relativismo y falta de conocimiento factual se realiza en la experiencia individual del espectador. Su preferencia por el museo y la galería demuestra los efectos y realidades paradójicos del capital y el éxito de artistas negros en la conquista de nuevos espacios de legitimación, participando por fin en un diálogo global. Protegidos por una amplia comunidad negra diaspórica, han de estar atentos a seguir siendo críticos y apuntando las quiebras del sistema, despertando fantasmas y mostrando los «sueños aplazados» (Hughes) de una comunidad en crecimiento marginada por el capital.

Recientemente, las redes y nodos de creación de discurso están desplazándose, revelándose como una constelación fragmentada, híbrida y mutable con la subjetividad 
y la reflexividad en el centro. ¿Cómo seguir cuestionando y desestabilizando el sistema geopolítico global donde se insiere la praxis artística desde sus posiciones privilegiadas?

\section{Bibliografía}

Akomfrah, John. (2013). DISSENT! John Akomfrah. Screening E Talk. Cinematek, Bruselas, 20 de noviembre de 2013. Texto de presentación. Recuperado de https://augusteorts.be/activities/12/john-akomfrah

Alter N. M., y T. Corrigan, (Eds.). (2017). Essays on the Essay Film. Nueva York, EE.UU.: Columbia University Press.

Álvarez E., (Ed.). (2016). Isaac Julien. Playtime E Kapital. Ciudad de México, México: MUAC.

Ballard T., y D. Kopel, (Eds.). (2018). John Akomfrah. Signs of Empire. Nueva York, EE.UU.: New Museum.

C\&. (10 de mayo de 2019). Golden Lion to Arthur Jafa. C\&. Recuperado de https://www.contemporaryand.com/magazines/golden-lion-to-arthur-jafa

Das J. (14 de marzo de 2019). Ghana makes a star-studded debut at the Venice Biennale. CNN Style. Recuperado de https://edition.cnn.com/style/article/ghana-venice-biennale-2019/ index.html

DeCarava R., y L. Hughes, (2018). The Sweet Flypaper of Life. Nueva York, EE.UU.: First Print Press.

Fanon F., (2002). Les Damnés de la terre, París, Francia.: La Découverte/Poche.

Frankel D., (Ed.). (2014). Isaac Julien. Riot. Nueva York, EE.UU.: MoMA

Gates Jr. H. L., (1992). The Black Man's Burden. En Wallace, M. Black Popular Culture. Seattle: EE.UU.: Bay Press.

Gilroy P., (1995). The Black Atlantic. Modernity and Double-Consciousness. Boston, EE.UU.: Harvard University Press.

Hall, S. (1987). Minimal Selves. Identity: The Real Me. ICA Document 6. Londres, Inglaterra: ICA y Verso.

Higgings Ch. (29 de marzo de 2019). Ghana shakes up art's 'sea of whiteness' with first Venice pavilion. The Guardian. Recuperado de https://www.theguardian.com/artanddesign/2019/ may/08/ghana-first-pavilion-venice-art-biennale-david-adjaye-ghanaian-artists-john-akomfrah

Jafa A. (29 de marzo de 2019). Love is he Message, the Message is Death. TATE. Recuperado de https://www.tate.org.uk/whats-on/tate-liverpool/exhibition/love-message-message-death

Julien I., y C. MacCabe, (1991). Diary of a Young Soul Rebel. Londres, Reino Unido: British Film Institute.

Lokale. P. (10 de septiembre de 2019). Yango 2020: la commissaire Nadia Yala Kisukiki dévoile une partie de ce rendez-vous artistique. Actualité.CD. Recuperado de https://actualite. cd/2019/09/10/yango-2020-la-commissaire-nadia-yala-kisukidi-devoile-une-partie-de-cerendez-vous

MacKenzie S. y A. Westerstahl, (Eds.). (2016). Films on Ice: Cinemas of the Artic, Edimburgo, Reino Unido: Edimburgh University Press.

Mbembe A. (2018). Politiques de l'inimitié. París, Francia: La Découverte.

Mercer K., (1994). Welcome to the Jungle. New Positions in Black Cultural Studies. Nueva York y Londres, EE.UU. y Reino Unido: Routledge.

The Otholit Group (2007). The Ghosts of Songs: The Art of the Black Audio Film Collective. Liverpool, Reino Unido: Liverpool University Press.

Van der Zee J., O. Dodson y C. Billops, (1978). The Harlem Book of the Dead. Nueva York, EE.UU.: Morgan \& Morgan. 